\title{
Selection and characterization of a precocious line of Eimeria media
}

\author{
Xiaolong Gu ${ }^{1,2} \cdot$ Hongbin $\mathrm{Liu}^{3} \cdot$ Chao $\mathrm{Li}^{1}$. Sufang Fang ${ }^{2} \cdot$ Ping Cui $^{2} \cdot$ Qin Liao $^{1} \cdot$ Sixin Zhang ${ }^{1} \cdot$ Si Wang ${ }^{1}$. \\ Chunhui Duan ${ }^{1} \cdot$ Fang $\mathrm{Yu}^{4} \cdot$ Xun Suo $^{1} \cdot$ Xianyong Liu $^{1}$
}

Received: 26 March 2019 / Accepted: 2 August 2019 / Published online: 12 August 2019

(C) Springer-Verlag GmbH Germany, part of Springer Nature 2019

\begin{abstract}
Coccidiosis, caused by the infection of Eimeria parasites, is one of the most common diseases in domestic rabbits. Live anticoccidial vaccine formulated with attenuated precocious lines of pathogenic eimerian parasites is expected to be valuable for the control of rabbit coccidiosis as a similar strategy to produce anticoccidial vaccines against chicken coccidiosis has being used for several decades. Eimeria media, moderate pathogenic, is widespread in China. Therefore, attenuated anticoccidial vaccines against rabbit coccidiosis should contain vaccine strain(s) of E. media. In this study, a precocious line of E. media (Empre) was selected by collecting and propagating the early excreted oocysts with 16 successive generations. The prepatent period of Empre reduced from $108 \mathrm{~h}$ of its parental strain (Emwt) to $70 \mathrm{~h}$. The fecundity of Empre was about 1/10 to 1/3 lower than that of Emwt. Each sporocyst of Empre sporulated oocyst contained only one large refractile body instead of two smaller ones seen in the parental strain. When vaccinated with $1 \times 10^{3}$ or $1 \times 10^{4}$ precocious line oocysts, the rabbits were completely protected against homologous challenge with the parental strain 14 days post challenge by terms of body weight gain and oocyst output counting, indicating the efficacy of Empre. Meanwhile, all immunized rabbits showed no clinical sign post immunization, indicating the safety of Empre. For coimmunization, $1 \times 10^{3}$ Empre oocysts and $5 \times 10^{2}$ oocysts of a precocious line of E. intestinalis (EIP8) were inoculated to each rabbit in a trial. No diarrhea or mortality was found after vaccination, and the weight gains of the vaccinated group were similar to that of unvaccinated-unchallenged control (UUC) group, while the weight gains of the vaccinated group were similar to that of unvaccinated-unchallenged control (UUC) group $(P>0.05)$, but significantly higher than that of UCC group $(P<0.01)$ after challenge, indicating it is safe and effective when using co-immunization. These results together show that Empre, as a precocious line, is a good candidate of precocious line of E. media for anticoccidial vaccine development.
\end{abstract}

Keywords Rabbit $\cdot$ Coccidiosis $\cdot$ Eimeria media $\cdot$ Precocious line $\cdot$ Vaccine

\section{Introduction}

Coccidiosis, caused by the infection of the genus Eimeria, is recognized as one of the major handicaps in rabbit breeding

Section Editor: Xing-Quan Zhu

Xianyong Liu

liuxianyong@cau.edu.cn

1 National Animal Protozoa Laboratory \& College of Veterinary Medicine, China Agricultural University, Beijing 100193, China

2 College of Animal Science and Technology, Hebei North University, Zhangjiakou 075000, China

3 Department of Pharmacology, Hebei North University, Zhangjiakou 075000, China

4 Laboratory of Anatomy of Domestic Animals, College of Veterinary Medicine, China Agricultural University, Beijing 100193, China
(Cowie-Whitney 1977). It causes considerable economic losses in intensive and semi-intensive production due to the decrease in weight gain, diarrhea, and even death (DrouetViard et al. 1997a, 1997b). For a long time, the control of rabbit coccidiosis was based on continuous administration of anticoccidial drugs in feed or in drinking water. The routinely use of anticoccidial drugs resulted in drug-resistant problems in rabbit farming (Coudert 1989; Peeters et al. 1988). As inoculation with live attenuated eimerian parasites could provide sufficient protection against the challenge with the homologous strains (Akpo et al. 2012; Bachene et al. 2018), it provides a practical way to develop the attenuated vaccine against rabbit coccidiosis.

To date, attenuated strains were obtained by precociousness selection of 6 Eimeria species, including Eimeria media (Licois et al. 1990, 1994; Coudert et al. 1995: Licois et al. 1995; Pakandl 2005; Pakandl and Jelínkova 2006; Akpo et al. 2012; Bachene et al. 2018; Li et al. 2018). Though 
E. media is moderate pathogenic, heavy infection with this parasite can interfere with digestion and absorption and even cause significant reduction of body weight gain (Licois et al. 1994). In addition, E. media is widespread in commercial rabbit husbandry (Coudert 1989; Jing et al. 2012). Therefore, the formulation of anticoccidial vaccines against rabbit coccidiosis should contain vaccine strain(s) of $E$. media.

This study describes the selection of a precocious line of $E$. media and the characterization of its reproduction, pathogenicity, and immunogenicity.

\section{Materials and methods}

\section{Experimental animals}

Coccidia-free rabbits were obtained through the chemotherapeutic method. The breeding rabbits routinely received a coccidiostat in their food (monensin $40 \mathrm{mg} / \mathrm{kg}$ or diclazuril $1 \mathrm{mg} / \mathrm{kg}$ ) (Coudert et al. 1988). Weaned rabbits were housed in HEPA-equipped isolators until 6 to 7 weeks old. Californian rabbits were used for precocious selection, while New Zealand rabbits were used for the tests of fecundity, excretion curve, endogenous development, pathogenicity, and immunogenicity. China Agricultural University Animal Ethics Committee approved all experimental procedures, and due attention was paid to the welfare of the animals (certified by Beijing Laboratory Animal employee, ID: 1114120800096).

\section{Selection for the precocious line of $E$. media}

Isolation of the E. media and selection for precociousness of this strain was performed following protocol described by Coudert et al. (1995). Briefly, oocysts were isolated from the fecal samples collected from a rabbit farm in Zhangjiakou in 2008. Single-oocyst infection was performed to isolate and propagate the pure strain of wild-type E. media (Emwt). The precocious line (Empre) was obtained by 16 successive collections of early oocysts shed in the feces by the rabbits inoculated with oocysts of the previous generation. The detailed performance of selection is summarized in Table 1. In order to confirm the stability of precocious parasite, the precocious line at passage 16 was consecutively propagated in the absence of selective pressure in rabbits. Three rabbits were individually inoculated with $5 \times 10^{3}$ oocysts of Empre, and the daughter oocysts were recovered from feces during days 3 to 10 post inoculation. Sporulated daughter oocysts were inoculated to other three rabbits with the same dose. This propagation without selection was repeated five times. The prepatent time in each generation was measured.
Table 1 Selection of the precocious line of E. media (Empre)

\begin{tabular}{lllll}
\hline $\begin{array}{l}\text { Oocyst } \\
\text { inoculated }\end{array}$ & $\begin{array}{l}\text { Number } \\
\text { of oocyst } \\
\text { given(10 }\end{array}$ & $\begin{array}{l}\text { Time after inoculation } \\
\text { when oocysts were } \\
\text { collected in feces and } \\
\text { caecum content (h) }\end{array}$ & $\begin{array}{l}\text { Prepatent } \\
\text { period }\end{array}$ & $\begin{array}{l}\text { Oocyst } \\
\text { obtained }\end{array}$ \\
\hline P0 & $\begin{array}{l}\text { Single } \\
\text { oocyst }\end{array}$ & $111-117$ & 114 & P1 \\
P1 & $5 \times 10^{3}$ & $111-115$ & 114 & P2 \\
P2 & $5 \times 10^{3}$ & $92-98$ & 96 & P3 \\
P3 & $5 \times 10^{3}$ & $90-94$ & 94 & P4 \\
P4 & $5 \times 10^{4}$ & $100-104$ & 103 & P5 \\
P5 & $5 \times 10^{4}$ & $95-99$ & 98 & P6 \\
P6 & $5 \times 10^{4}$ & $88-93$ & 91 & P7 \\
P7 & $5 \times 10^{4}$ & $88-93$ & 91 & 98 \\
P8 & $5 \times 10^{4}$ & $90-101$ & 93 & P9 \\
P9 & $5 \times 10^{4}$ & $87-90$ & 90 & P10 \\
P10 & $1 \times 10^{5}$ & $88-96$ & 91 & P11 \\
P11 & $1 \times 10^{5}$ & $87-91$ & 90 & P12 \\
P12 & $1 \times 10^{5}$ & $86-92$ & 89 & P13 \\
P13 & $2 \times 10^{5}$ & $76-82$ & 79 & P14 \\
P14 & $2 \times 10^{5}$ & $76-96$ & 79 & P15 \\
P15 & $2 \times 10^{5}$ & $67-73$ & 70 & P16 \\
\hline & & & & \\
\hline
\end{tabular}

Morphological comparison between Emwt and Empre

The photographs of sporulated oocysts and sporocysts were taken using laser confocal microscopy (Leica SP5, Germany). The length and width of 100 oocysts for Empre or Emwt were individually measured with the Leica LAS AF software. Sporocysts of Empre and Emwt were released from oocysts by vortexing with 1-mm glass beads (Cha et al. 2014). Sporozoites were collected from excysted sporocysts by purifying with an anion exchange column of DE-52 (Schmatz et al. 1984). Sporozoites were fixed with $2.5 \%$ glutaraldehyde and then subjected to transmission electron microscopic photographs (EM-100CXII/S, Japan).

\section{Oocyst output comparison between Emwt and Empre}

Twenty-four rabbits were divided into six groups. Five groups of rabbits were inoculated with Empre at doses of $1 \times 10^{2}, 3 \times 10^{2}, 5 \times 10^{2}, 1 \times 10^{3}$, or $5 \times 10^{3}$, respectively. The sixth group of rabbits was inoculated with Emwt at dose of $5 \times 10^{3}$. The feces of Empre-inoculated rabbits were collected per group between days 3 and 10 post inoculation and subjected to oocyst counting following the method previously described by Licois and Coudert (1980). The feces of Emwt-inoculated rabbits were collected between days 4.5 and 12.5 post inoculation and subjected to oocyst counting. 


\section{Endogenous development study}

Ten rabbits were separately inoculated with oocysts of Emwt or Empre and euthanized at time points indicated in Table 2. Tissue samples were taken from duodenum, middle jejunum, and ileum, then fixed in $10 \%$ formaldehyde solution for $72 \mathrm{~h}$ and embedded in paraffin. Tissue sections, approximately $5 \mu \mathrm{m}$ thick, were cut, stained with hematoxylin and eosin, and studied by light microscopy (Olympus DX71 fluorescence microscope). Due to the lower multiplication rate of the precocious line, the doses of oocysts given for studying the beginning of their life cycle were higher.

\section{Test of pathogenicity and immunogenicity}

Thirty-two rabbits were divided into eight groups. Six groups (VC) of rabbits were vaccinated with Emwt or Empre at doses of $1 \times 10^{2}, 1 \times 10^{3}$, or $1 \times 10^{4}$, respectively. The other two groups were unvaccinated and unchallenged control (UUC) and unvaccinated and challenged control (UCC). The rabbits in VC groups and UUC group were used to test the pathogenicity of Empre and Emwt. In order to test the immunogenicity of Empre, the rabbits in Empre-vaccinated groups and UCC group were challenged with $1 \times 10^{4}$ Emwt oocysts on day 14 post vaccination.

The feces of inoculated animals were collected per group between days 3 and 10 post vaccination, and total oocyst output was calculated for both Emwt and Empre. Oocyst counting was also carried out from days 4 to 11 post challenge.

Clinical signs (depression, diarrhea, death) were observed for all animals during the whole assay. Body weight was measured at days 0,14 , and 28 post vaccination.

\section{Co-immunization assay}

To test the effect of co-immunization of precocious lines of coccidia on rabbits, we carried out a trial using Empre and EIP8, a precocious line of E. intestinalis recently selected ( $\mathrm{Li}$ et al. 2018). Total of 12 rabbits were divided into three groups: vaccinated and challenged (VC), unvaccinatedunchallenged control (UUC), and unvaccinated-challenged control (UCC). Rabbits in VC group were inoculated with $1 \times 10^{3}$ Empre sporulated oocysts and $5 \times 10^{2}$ EIP 8 sporulated oocysts. At the 14th day post inoculation, the rabbits except

Table 2 Intervals of sampling of tissue and inoculation dose in the experiment

\begin{tabular}{|c|c|c|c|c|c|c|c|}
\hline Hour (h) & & 24 & 42 & 60 & 70 & 96 & 108 \\
\hline \multirow[t]{2}{*}{ Dose } & Emwt & $1 \times 10^{7}$ & $1 \times 10^{7}$ & $5 \times 10^{6}$ & $1 \times 10^{6}$ & $1 \times 10^{6}$ & $1 \times 10^{6}$ \\
\hline & Empre & $2 \times 10^{7}$ & $1 \times 10^{7}$ & $1 \times 10^{7}$ & $5 \times 10^{6}$ & & \\
\hline
\end{tabular}

those in UUC group were challenged with $1 \times 10^{4}$ Emwt oocysts and $1 \times 10^{4}$ oocysts of wild type of E. intestinalis (Eiwt). Body weight was measured at days $0,7,14,21$, and 28 post immunization. Total oocyst output was measured for two groups of challenged animals from days 4 to 14 after challenge. Then, the oocyst output of Emwt and Eiwt was calculated based on the percentage of the two parasites, which are morphologically different as oocysts of Emwt were ellipsoid or ovoid while oocysts of Eiwt were piriform (Pakandl 2009).

\section{Statistical analysis}

Statistical analysis was performed by one-way ANOVA of SPSS software (Version 17.0). Data were expressed as mean \pm standard deviation; * indicates $P<0.05$, ** indicates $P<0.01$, and *** indicates $P<0.001$.

\section{Results}

\section{Selection of the precocious line of Eimeria media}

After 16 successive propagations under selection pressure, the prepatent period of the precocious line Empre reduced from 114 to $70 \mathrm{~h}$. The prepatent period was distinctly decreased during the passages of P3, P7, P14, and P16 (Table 1). This shortened prepatent period of Empre was maintained after five generations of successive passages without selection pressure.

\section{Comparison of oocyst morphology, oocyst production, and endogenous development between Emwt and Empre}

To determine whether oocyst size was altered following selection, freshly sporulated Empre and Emwt oocysts (100 oocysts each) were examined by light microscopy. Oocyst size of Empre was $(30.6 \pm 2.2 \mu \mathrm{m}) \times(18.5 \pm 1.4 \mu \mathrm{m})$, while that of Emwt was $(29.9 \pm 3.4 \mu \mathrm{m}) \times(18.2 \pm 1.0 \mu \mathrm{m})$. The length-towidth ratios of Empre and Emwt were 1.66. There was not a significant difference $(P>0.05)$ in oocyst size between Empre and Emwt. In Emwt sporulated oocysts, a small refractile body (RB) could be seen in each sporozoite (Fig. 1a-e); while only a large RB could be observed within each sporocyst of Empre sporulated oocysts and the RB was free in the sporocyst (Fig. $1 b-f)$.

The peak of oocyst shedding occurred on day 5 for Empre, whereas it was on day 6.5 for Emwt (Fig. 1b). The oocyst output for rabbits inoculated with $5 \times 10^{3}$ Empre oocysts was $6.6 \times 10^{7}$; it was $2.0 \times 10^{8}$ for those inoculated with $5 \times$ $10^{3}$ Emwt oocysts (Fig. 1b). The total oocyst output of Empre was $1 / 3$ that of the Emwt.

In both Empre- and Emwt-infected rabbits, schizonts emerged at $24 \mathrm{~h}$ post inoculation (Fig. 2a and b). The second 
a
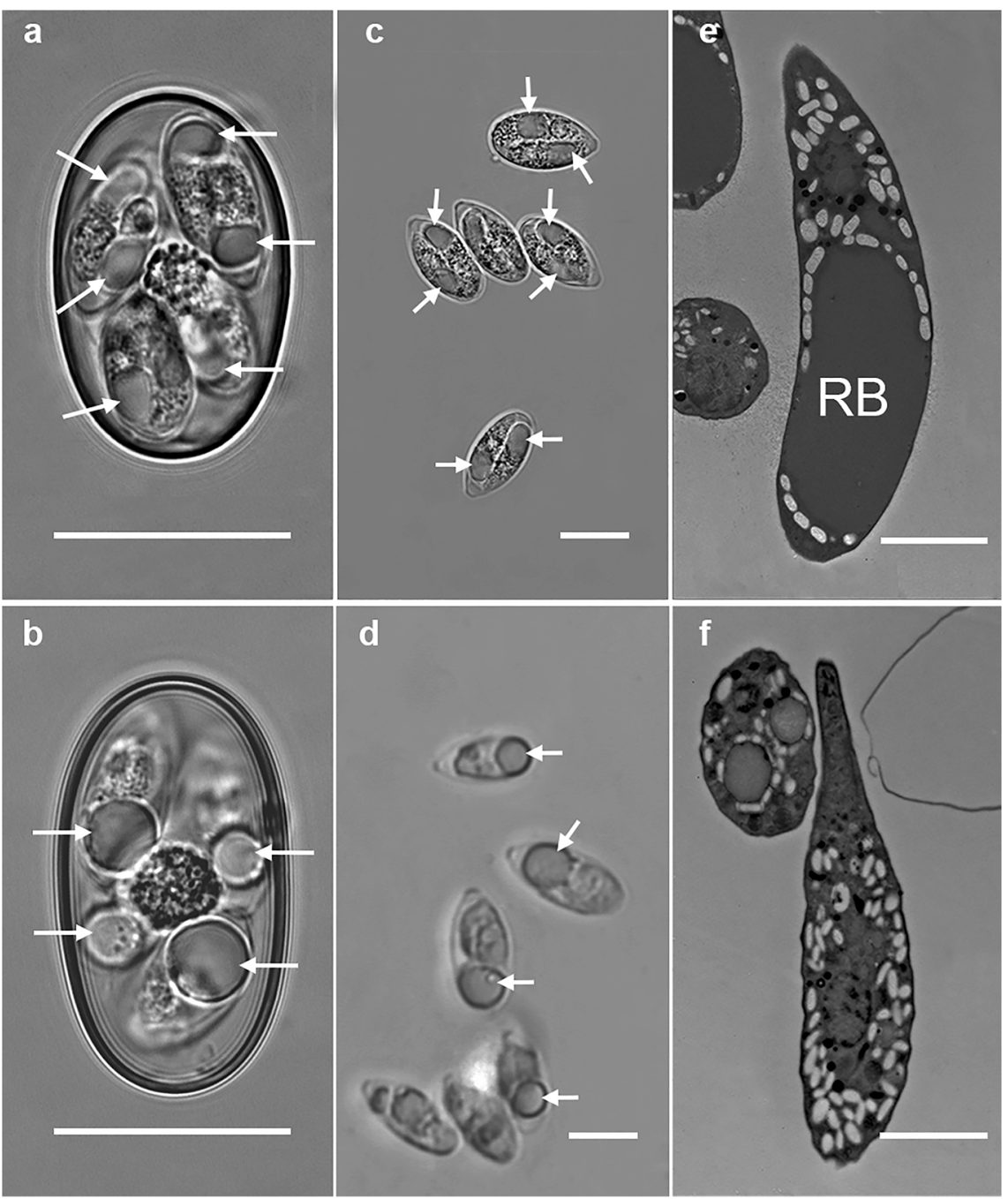

b

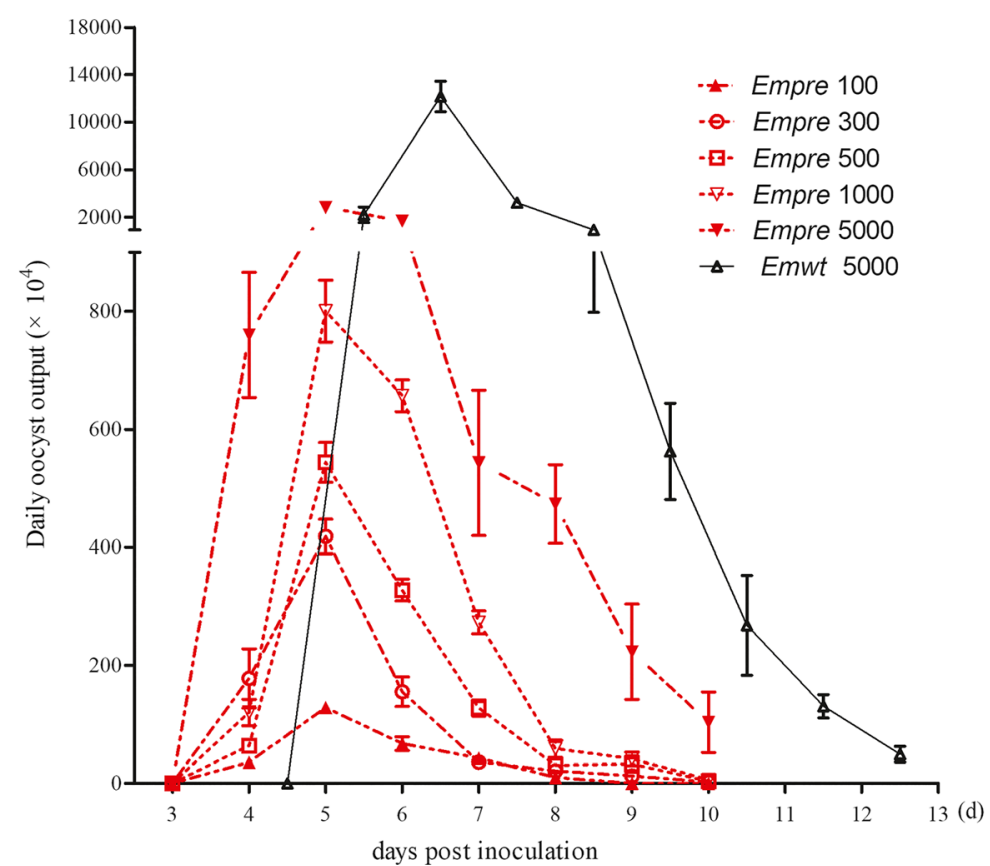


Fig. 1 Comparison of morphology (a) and oocyst production (b) between Empre and Emwt. Light arrow: refractile body (RB). a Emwt sporulated oocyst. b Empre sporulated oocyst. c Emwt sporocyst. d Empre sporocyst. e Emwt sporozoite. f Empre sporozoite. Bar $=20 \mu \mathrm{m}$ (a, b); Bar $=5 \mu \mathrm{m}(\mathbf{c}, \mathbf{d}) ; B a r=2 \mu \mathrm{m}(\mathbf{e}, \mathbf{f}) . B$, oocyst output curve of Empre and Emwt. Each rabbit was inoculated with $1 \times 10^{2}, 3 \times 10^{2}, 5 \times$ $10^{2}, 1 \times 10^{3}, 5 \times 10^{3}$ Empre oocysts or $5 \times 10^{3}$ Emwt oocysts, respectively $(N=4)$. Fecal samples were collected daily from days 3 to day 10 post inoculation for Empre or daily from days 4.5 to day 12.5 post inoculation for Emwt

generation schizonts were detected at $42 \mathrm{~h}$ (Fig. $2 \mathrm{c}$ and d). At $60 \mathrm{~h}$ post infection with Empre, macrogamonts could be detected in epithelial cells (Fig. 2e). At $70 \mathrm{~h}$ post infection with Empre, oocysts could be detected (Fig. 2g). In contrast, in Emwt-infected rabbits, the third generation of schizonts was detected at $70 \mathrm{~h}$ post infection (Fig. $2 \mathrm{~h}$ ), while gametocytes and oocysts were detected at $96 \mathrm{~h}$ post infection (Fig. 2i). By $108 \mathrm{~h}$ post infection, more Emwt oocysts could be detected (Fig. 2j).

\section{Pathogenicity and immunogenicity}

To evaluate the pathogenicity of Empre and Emwt, six groups of rabbits were inoculated with Emwt or Empre at doses of $10^{2}, 10^{3}$, or $10^{4}$, respectively. No diarrhea or loss of body weight was detected in these Empre-immunized groups. In contrast, mild and short-time diarrhea was found in the rabbits inoculated with $10^{4}$ Emwt oocysts during days 4 to 6 post inoculation. Compared with UUC group, rabbits infected with $10^{3}$ or $10^{4}$ Emwt oocysts lost $41.4 \%$ or $51.7 \%$ of their weight gain on average (totally $217 \mathrm{~g}$ and $270 \mathrm{~g}$ ) from days 0 to 14 post inoculation. In contrast, the weight gains of rabbits infected with Empre oocysts were similar to that of UUC group (totally $524 \mathrm{~g}$ ) from days 0 to 14 post inoculation (Fig. 3a). Meanwhile, the fecundity of Empre was also detected. When inoculated with $10^{2}$ oocysts, a single rabbit excreted $2.8 \times 10^{6}$ Empre oocysts on average, whereas $2.8 \times 10^{7}$ Emwt oocysts on average. When inoculated with $10^{4}$ oocysts, a single rabbit excreted $9.2 \times 10^{7}$ Empre oocysts or $2.5 \times 10^{8}$ Emwt oocysts on average. The fecundity of Empre was about $1 / 3$ to $1 / 10$ that of the Emwt. (Fig. 3c).

To further determine the immunogenicity of Empre, rabbits inoculated with $10^{2}, 10^{3}$, or $10^{4}$ Empre oocysts were challenged with $10^{4}$ Emwt oocysts on day 14 post inoculation and both body weight gain and oocyst production were measured. From 4 to 6 days post challenge, rabbits in UCC group presented mild diarrhea. Interestingly, no diarrhea was found in all Empre-immunized rabbits post challenge. Weight gain of rabbits immunized with Empre oocysts at each doses $\left(10^{2}\right.$, $10^{3}$, and $10^{4}$ ) was similar to that of the UUC group animals ( $35 \mathrm{~g}$ per day on average from days 0 to 14 post challenge). On the other hand, rabbits in the UCC group showed a significant decrease of body weight gain from days 0 to 14 post challenge
( $15 \mathrm{~g}$ per day on average from days 0 to 14 post challenge). In contrast, rabbits inoculated with $10^{3}$ or $10^{4}$ Empre oocysts increased the body weight gain on average ( $39.3 \mathrm{~g}$ per day or $38.5 \mathrm{~g}$ per day) from days 0 to 14 post challenge, while rabbits immunized with $10^{2}$ Empre gained less weight gain ( $27.1 \mathrm{~g}$ per day) than that of the UUC animals from days 0 to 14 post challenge (Fig. $3 b$ ).

In all study groups, when the body weight gain from day 14 post challenge was calculated, there was no significant difference between Empre-immunized groups and UUC group (Fig. $3 b)$. After challenge, oocyst production in VC groups immunized with $10^{2}, 10^{3}$, and $10^{4}$ Empre oocyst were $38.7 \%, 6.2 \%$, and $1.1 \%$ of that of the UCC group, respectively (Fig. 3d).

\section{Protection against homologous challenge after co-immunization}

After co-immunization or co-challenge with two species, no diarrhea was found in VC group and UUC group, while three of four rabbits in the UCC group presented severe diarrhea. After vaccination, the body weight gain of $\mathrm{VC}$ group was similar to that of UUC group on day 7 ( $23 \mathrm{~g}$ per day on average) and day 14 (32 g per day on average). After challenge, the body weight gain of $\mathrm{VC}$ group was similar to that of UUC group on day 21 ( $23 \mathrm{~g}$ per day on average) and day 28 (26 g per day on average) post vaccination, but significantly higher than that of the UCC group $(P<0.01)$ (Fig. 4a).

For Empre orEIP8, over $1 \times 10^{7}$ oocysts per animal were obtained in VC group between day 3 and day 10 after coimmunization. After challenge, oocyst output of Emwt in VC group was $2.1 \%$ of that of UCC group, and oocyst output of Eiwt in VC group was $0.9 \%$ of that of UCC group (Fig. 4b).

\section{Discussion}

In this study, we selected and characterized a precocious line of E. media. Compared with its parental strain Emwt, the precocious line Empre is characterized by a shortened prepatent period (from 108 to $70 \mathrm{~h}$ ), a single refractile body in each sporocyst of an oocyst, remarkably reduced oocyst production, and highly immunogenic.

Licois et al. (1994) reported a precocious line of Eimeria media, which is similar to Empre of this study in terms of prepatent time, fecundity, and oocyst morphology. Observation of endogenous development of both Empre and Emwt showed that oocyst formation occurred around $70 \mathrm{~h}$ after inoculation with Empre, while meronts of third generation of merogony were majorly found in Emwt-infected animals, which may suggest the deletion of third generation of merogony and thus the shortening of the prepatent time in the precocious line Empre. 
Fig. 2 Observation of

endogenous development of

Empre and Emwt in middle jejunum. Arrow(s) indicate the parasite(s) in the panels. a, b First-generation schizonts. $\mathbf{c}$ and d Second-generation schizonts. e Gametocytes of Empre. f Mature schizonts of Emwt. g Oocysts of Empre. $\mathbf{h}$ Third-generation schizonts. i Gametocytes of Emwt. j Oocysts of Emwt. $\mathrm{Bar}=20 \mu \mathrm{m}$
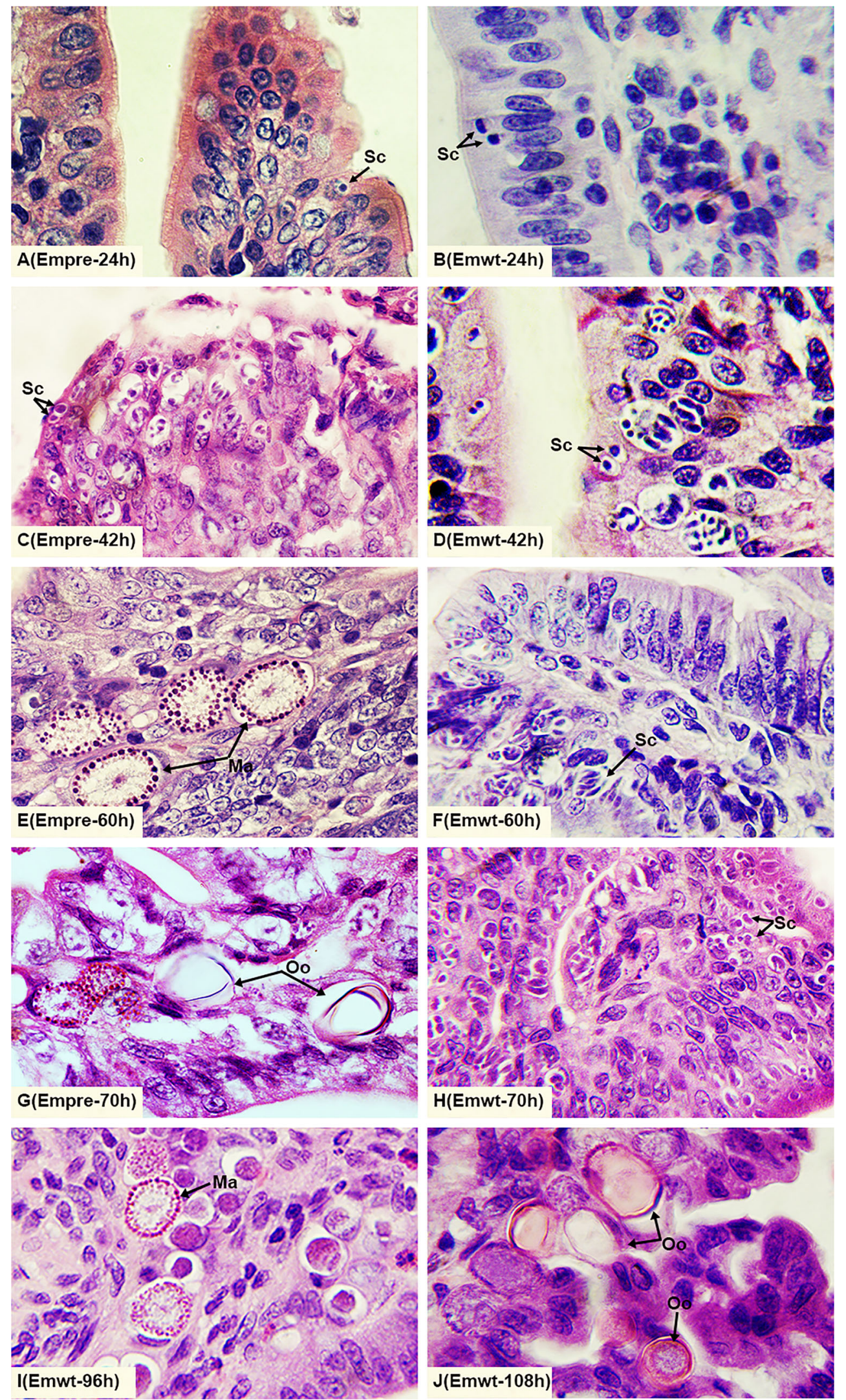


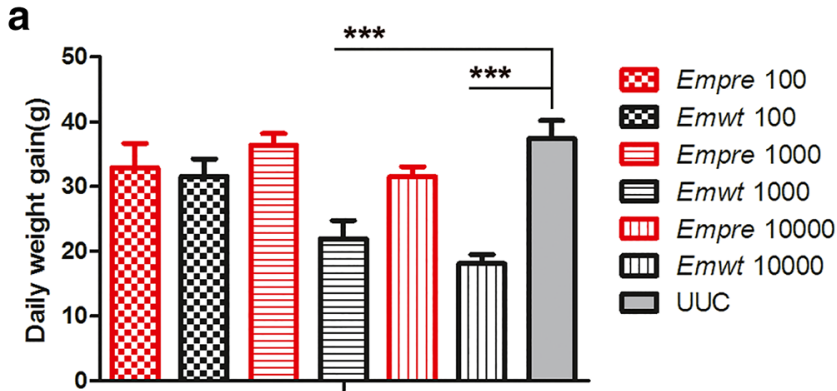

14 days post immunization

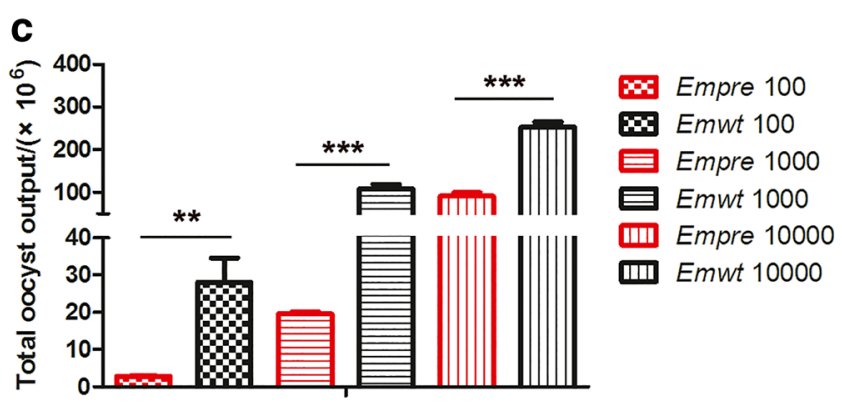

3-10 days post immunization

Fig. 3 Pathogenicity and immunogenicity of Empre. Rabbits were inoculated with $1 \times 10^{2}, 1 \times 10^{3}$, and $1 \times 10^{4}$ Empre or Emwt oocysts, respectively. Challenge infection was performed to rabbits except for those in UUC group and Emwt-inoculated group 14 days post

Previous studies showed that the position, the size, and the number of RB changed when most precocious lines of rabbit coccidia were obtained from their parental strains (Pakandl et al. 2001; Pakandl and Jelínkova 2006). In this study, a large RB was seen in each sporocyst of oocyst in Empre, similar to the observation of a previously selected precocious line of E. media (Licois et al. 1994). The RB is generally present in the sporozoite stage, fragmented during merogony and incorporated into the forming second-generation merozoites (Lal et al. 2009). During the selection of Empre, both types of $\mathrm{RB}$ were found in sporocysts of a minor proportion of oocysts

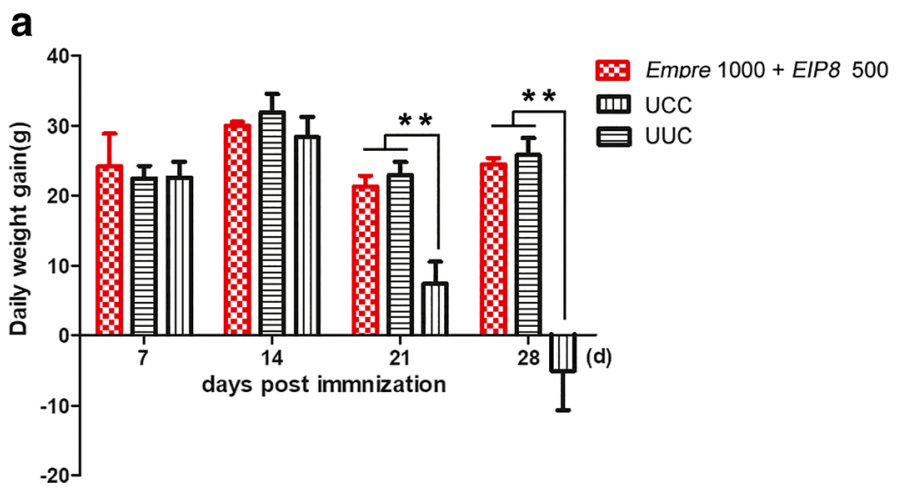

Fig. 4 Protection against homologous challenge after co-immunization with precocious lines of $E$. media and $E$. intestinalis. Rabbits were inoculated with $10^{3}$ Empre oocysts and $5 \times 10^{2}$ EIP 8 oocysts, then challenged with $1 \times 10^{4}$ Emwt oocysts and $1 \times 10^{4}$ oocysts of wild type of E. intestinalis (Eiwt) 14th day post inoculation. a Body weight gain post b
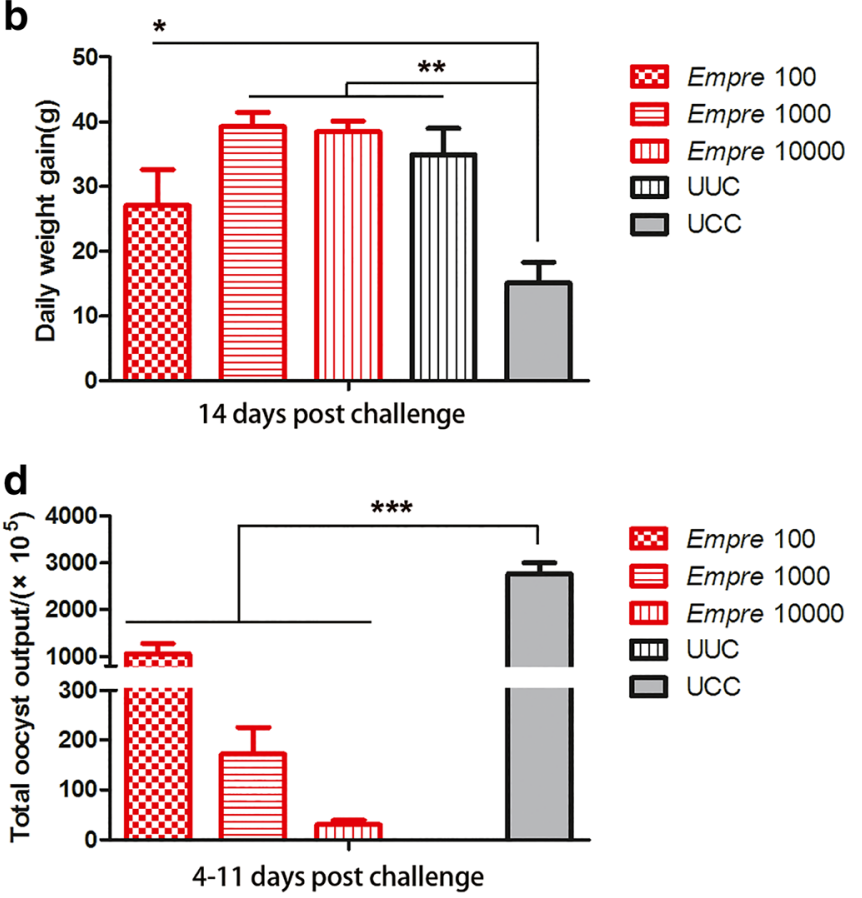

immunization. Body weight gain was measured post immunization (a) and post challenge (b), while total oocyst output was counted days 3 to 10 post immunization (c) and days 4 to 11 post challenge (d). $* P<0.05$; ** $P<0.01 ; * * * P<0.001$

for the middle generations (data not shown), which indicates that the alter of RB may precede the reduction of the schizogony generation. Together with the deduction of the deletion of third generation of merogony in Empre, this observation further prompt a hypothesis that RB may function in maintaining the merogony generations of eimerian parasites.

Two proteins, $\mathrm{SO} 7$ and Eimepsin, the most abundant protein identified in Eimeria sporozoites, are located at the RB (de Venevelles et al. 2004). Some groups have proposed a role for eimepsin and $\mathrm{SO} 7$ in the invasion process and intracellular development (Danforth and Augustine 1989; Augustine 1999,

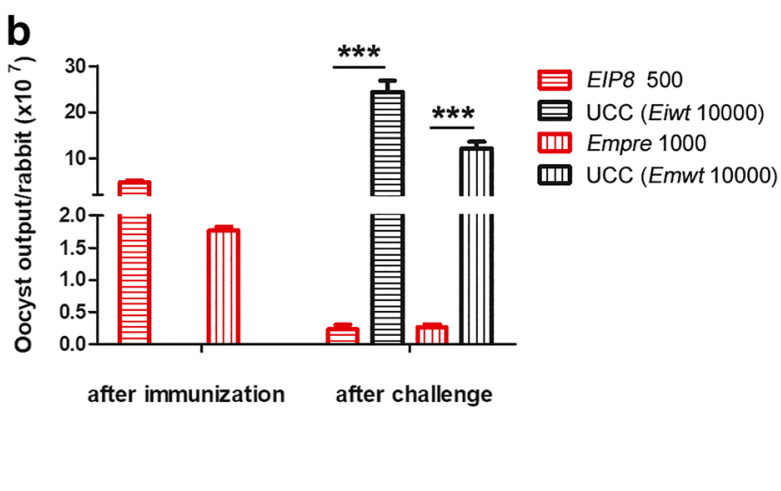

co-immunization and post challenge. b Total oocyst output post coimmunization and post challenge. Oocyst output was detected daily from days 3 to day 10 post immunization and days 4 to post challenge. $* P<0.05 ; * * P<0.01 ; * * * P<0.001$ 
2001; Jean et al. 2000). The Eimeria RB protein eimepsin is similar to the plasmepsins, proteases from Plasmodium that degrade heme in the food vacuole (Liu et al. 2005). Proteomic studies revealed that RB contains proteins such as Eimepsin, $\mathrm{SO} 7$, haloacid dehalogenase, hydrolase, subtilase, lactacte dehydrogenase, or ubiquitin family proteins (de Venevelles et al. 2006). The presence of other enzymes, such as lactate dehydrogenase, indicates RB has energetic and metabolic functions in this parasite (Lal et al. 2009; Lemgruber and Lupetti 2012).

In future work, the different proteins of RBs between the parental strain and the precocious line will be identified by a comparative proteomics approach, and the candidate proteins that may function in maintaining the schizogony generations of Eimeria will be chosen and validated.

In conclusion, the precocious line of E. media selected in this study is immunogenic and thus can be a candidate line for the development of live anticoccidial vaccine for the control of the rabbit coccidiosis.

Funding information This research was supported by China Agricultural Research System (CARS-43), the National Natural Science Foundation of China (31572507 and 31472180), the Major Project of Hebei North University (ZD201308), and Project of Hebei Provincial Education Department (QN20131091).

Compliance with ethical standards Experiments were approved by China Agricultural University Laboratory Animal Welfare and Animal Experimental Ethical Inspection Committee (CAU20160921-2). Animal experiments were carried out in accordance with Chinese National Laboratory Animal Standards (GB 14925-2010/ XG1-2011). Enough food and water were provided. Handling of animals was minimal when they were inoculated and weighed. Fecal samplings were performed outside the rabbit cages. Rabbits were euthanized in a humane manner.

Conflict of interest The authors declare that they have no conflict of interest.

\section{References}

Akpo Y, Kpodékon MT, Djago Y, Licois D, Youssao IA (2012) Vaccination of rabbits against coccidiosis using precocious lines of Eimeria magna and Eimeria media in Benin. Vet Parasitol 184:7376

Augustine PC (1999) Reduced invasion of cultured cells pretreated with a monoclonal antibody elicited against refractile body antigens of avian coccidial sporozoites. J Eukaryot Microbiol 46:254-258

Augustine PC (2001) Invasion of different cell types of sporozoites of Eimeria species and effects of monoclonal antibody 1209-C2 on invasion of cells by sporozoites of several apicomplexan parasites. J Eukaryot Microbiol 48:177-181

Bachene MS, Temim S, Ainbaziz H, Bachene A, Suo X (2018) A vaccination trial with a precocious line of Eimeria magna in Algerian local rabbits Oryctolagus cuniculus. Vet Parasitol 261:73-76

Cha J, Talha AFSM, Lim C, Kim B (2014) Effects of glass bead size, vortexing speed and duration on Eimeria acervulina oocyst excystation. Exp Parasitol 138:18-24
Coudert P (1989) Some peculiarities of rabbit coccidiosis. In: Coccidia and Coccidiomorphs. Vth International Coccidiosis Conference, Tours, pp 481-488

Coudert P, Licois D, Besnard J (1988) Establishment of a SPF breeding colony without hysterectomy and hand rearing procedures. In: Holdas, S. (ed.) Proc. 4th Congr. World Rabbit Sci Assoc. Budapest. pp 137-148

Coudert P, Licois D, Drouet-Viard F (1995) Eimeria species and strains of rabbits. In biotechnology guidelines on techniques in coccidiosis research. The European Commission DGXII, Luxembourg, pp 52-73

Cowie-Whitney J (1977) Diseases of the commercial rabbit. Vet Rec 101: 299-303

Danforth HD, Augustine PC (1989) Eimeria tenella: use of a monoclonal antibody in determining the intracellular fate of the refractile body organelles and the effect on in vitro development. Exp Parasitol 68: $1-7$

Drouet-Viard F, Coudert P, Licois D, Boivin M (1997a) Vaccination against Eimeria magna coccidiosis using spray dispersion of precocious line oocysts in the nest box. Vet Parasitol 70:61-66

Drouet-Viard F, Coudert P, Licois D, Boivin M (1997b) Acquired protection of the rabbit (Oryctolagus cuniculus) against coccidiosis using a precocious line of Eimeria magna: effect of vaccine dose and age at vaccination. Vet Parasitol 69:197-201

Jean L, Grosclaude J, Labbé M, Tomley F, Péry P (2000) Differential localisation of an Eimeria tenella aspartyl proteinase during the infection process. Int J Parsitol 30:1099-1107

Jing F, Yin G, Liu X, Suo X, Qin Y (2012) Large-scale survey of the prevalence of Eimeria infections in domestic rabbits. Parasitol Res 110:1495-1500

Lal K, Bromley E, Oakes R, Prieto JH, Sanderson SJ, Kurian D, Hunt L, Yates JRIII, Wastling JM, Sinden RE, Tomley FM (2009) Proteomic comparison of four Eimeria tenella life-cycle stages: Unsporulated oocyst, sporulated oocyst, sporozoite and second-generation merozoite. Proteomics 9:4566-4576

Lemgruber L, Lupetti P (2012) Crystalloid body, refractile body and virus-like particles in Apicomplexa: what is in there? Parasitology 139:285-293

Li C, Tao G, Gu X, Cui Y, Wang Y, Suo J, Lv Y, Yu F, Mamoun CB, Suo X, Liu X (2018) Selection and identification of an Eimeria intestinalis precocious line with enlarged oocysts and deletion of one generation of schizogony. Parasitol Res 118:969-976

Licois D, Coudert P (1980) Attempt to suppress immunity in rabbits immunized against Eimeria intestinalis. Ann Rech Vet 11:273-278

Licois D, Coudert P, Boivin M, Drouet-Viard F, Provot F (1990) Selection and characterization of a precocious line of Eimeria intestinalis, an intestinal rabbit coccidium. Parasitol Res 76:192-198

Licois D, Coudert P, Drouet-Viard F, Boivin M (1994) Eimeria media: selection and characterization of a precocious line. Parasitol Res 80 : $48-52$

Licois D, Coudert P, Drouet-Viard F, Boivin M (1995) Eimeria magna: pathogenicity, immunogenicity and selection of a precocious line. Vet Parasitol 60:27-35

Liu J, Gluzman IY, Drew ME, Goldberg DE (2005) The role of Plasmodium falciparum food vacuole plasmepsins. J Biol Chem 280:1432-1437

Pakandl M (2005) Selection of a precocious line of the rabbit coccidium Eimeria flavescens Marotel and Guilhon (1941) and characterisation of its endogenous cycle. Parasitol Res 97:150-155

Pakandl M (2009) Coccidia of rabbit: a review. Folia Parasitol 56:153-166

Pakandl M, Jelínkova A (2006) The rabbit coccidium Eimeria piriformis: selection of a precocious line and life-cycle study. Vet Parasitol 137: 351-354

Pakandl M, Licois D, Coudert P (2001) Electron microscopic study on sporocysts and sporozoites of parental strains and precocious lines of rabbit coccidia Eimeria intestinalis, E. media and E. magna. Parasitol Res 87:63-66 
Peeters JE, Geeroms R, Halen P (1988) Evolution of coccidial infection in commercial and domestic rabbits between 1982 and 1986. Vet Parasitol 29:327-331

Schmatz DM, Crane MS, Murray PK (1984) Purification of Eimeria sporozoites by DE-52 anion exchange chromatography. J Protozool 31:181-183

de Venevelles P, Chich JF, Faigle W, Loew D, Labbé M, Girard-Misguich F, Péry P (2004) Towards a reference map of Eimeria tenella sporozoite proteins by two-dimensional electrophoresis and mass spectrometry. Int J Parsitol 34:1321-1331 de Venevelles PD, Chich JF, Faigle W, Lombard B, Loew D, Pery P, Labbe M (2006) Study of proteins associated with the Eimeria tenella refractile body by a proteomic approach. Int J Parsitol 36: 1399-1407

Publisher's note Springer Nature remains neutral with regard to jurisdictional claims in published maps and institutional affiliations. 